\title{
The Patterns of Blood Groups and Its Association with Blood Donation in Saudi Arabia
}

\author{
Fahad A. Alateeq ${ }^{*}$, Thamer Z. Aldugieman ${ }^{2}$, Yousef Duhaim A. Al-Rashdi', \\ Abdul Rahman Ali A. Alsogair', Saleh Hadi Alharbi', Ibrahim Bin Ahmed, \\ Hussain Gadelkarim Ahmed ${ }^{2}$ \\ ${ }^{1}$ Faculty of Medicine, Al Imam Mohammad Ibn Saud Islamic University, Riyadh, Kingdom of Saudi Arabia (KSA) \\ ${ }^{2}$ College of Medicine, University of Hail, Hail, Kingdom of Saudi Arabia (KSA) \\ Email: ${ }^{\star}$ hussaingad5@gmail.com
}

How to cite this paper: Alateeq, F.A., Aldugieman, T.Z., Al-Rashdi, Y.D.A., Alsogair, A.R.A.A., Alharbi, S.H., Ahmed, I.B. and Ahmed, H.G. (2018) The Patterns of Blood Groups and Its Association with Blood Donation in Saudi Arabia. Open Journal of Preventive Medicine, 8, 291-300. https://doi.org/10.4236/ojpm.2018.89025

Received: August 31, 2018

Accepted: September 22, 2018

Published: September 25, 2018

Copyright $(0) 2018$ by authors and Scientific Research Publishing Inc. This work is licensed under the Creative Commons Attribution International License (CC BY 4.0).

http://creativecommons.org/licenses/by/4.0/

\begin{abstract}
Background: Blood groups system has key importance for transfusion safety and clinical practice. Therefore, the objective of the present study was to evaluate the distribution of $\mathrm{ABO}$ blood groups and its association with blood donation in Saudi Arabia. Methodology: In this study, we collected information regarding blood donation from 715 Saudi volunteers living in the city of Hail, Northern Saudi Arabia. Data about blood donation were obtained from 715 Saudi volunteers living in the city of Hail. Results: The majority of the study population was found with group $B+$ representing 174 participants, followed by $\mathrm{A}+, \mathrm{O}+, \mathrm{AB}+, \mathrm{B}$-ve, $\mathrm{A}$-ve, $\mathrm{AB}$-ve and $\mathrm{O}$-ve, representing 165, 153, 47, 29, 20, 9, and 7 participants, in this order. Conclusion: The major blood group among Saudi population is group $\mathrm{B}+$ followed by group $\mathrm{A}+$ and $\mathrm{O}+$. Individuals with rare blood groups were less likely to participate in blood donation programs, which necessitate the need for educational programs using motivating factors.
\end{abstract}

\section{Keywords}

Blood Donation, Donors, Saudi Arabia, Voluntary Donation, ABO Group

\section{Introduction}

In spite of a stable rise in blood donation and voluntary non-remunerated blood donors, many countries continue to have numerous challenges with its blood donation service. To ensure a sufficient and safe blood supply that meets the increasing clinical need for blood products, there is an urgent need to strengthen 
the country's blood donor management [1]. An integrated strategy for blood safety is required for the provision of safe and adequate blood. Recruiting a sufficient number of safe blood donors is an emerging challenge. The shortage of blood in India is due to an increase in the demand, with fewer voluntary blood donors [2].

Towards 100\% Voluntary Blood Donation: A Global Framework for Action is global framework for action to achieve $100 \%$ voluntary blood donation that has been developed jointly by the World Health Organization and the International Federation of Red Cross and Red Crescent Societies. It is designed to provide guidance and support to countries seeking to establish effective voluntary blood donor programs, phase out family/replacement blood donation and eliminate paid donation [3].

$\mathrm{ABO}$ and $\mathrm{RhD}$ blood groups, the most well-known blood group systems, are of key importance for transfusion safety and clinical practice and are also thought to be linked with disease susceptibility [4]. The distribution of ABO and $\mathrm{RhD}$ blood groups varies globally [5]. Ethnicities differ in prevalence of blood groups and antigens. Substantial donor-recipient mismatch within mixed-ethnic societies may render certain recipients at higher risk for alloimmunization [6]. Compared to European frequencies, substantial antigen differences were found between individuals of African, Asian, Native American, and Polynesian origin [7] [8] [9] [10]. Data regarding antigen distribution within Saudi by ethnicity is limited. Reference intervals for venous blood parameters differ with age, gender, geographic region, and ethnic groups. Hence, local laboratory reference intervals are important to improve the diagnostic accuracy of health assessments and diseases [11]. However, there has been no previous study reported $\mathrm{ABO}$ and $\mathrm{RhD}$ blood groups reference intervals from Saudi Arabia. Therefore, the objective of the present study was to evaluate the distribution of $\mathrm{ABO}$ blood groups and its association with blood donation in Saudi Arabia.

\section{Materials and Methods}

\subsection{Study Design}

In this study we collected information regarding blood donation from 715 Saudi volunteers living the city of Hail, Northern Saudi Arabia during the period from September 2017 to May 2018. Data about blood donation were obtained from 715 Saudi volunteers living in the city of Hail. Participants were randomly selected by simple random regardless to age, gender and education or occupation.

A Purposeful questionnaire was designed and used for obtaining of the necessary data. The following information was obtained from each participant: age, sex, and education level and occupation sector. Questions regarding awareness about blood donation were also included, which comprised: Blood group type, Previous donation, I gave an obligatory donation, I gave voluntary donation, Donation Frequency, Will you intend to donate in the future, If there is announcement for your blood group will response? Are worry from blood donation. 


\subsection{Ethical Consent}

Each participant was asked to sign a written ethical consent during the questionnaire's interview. The informed ethical consent form was designed and approved by the ethical committee of the College of Medicine (University of Hail, Saudi Arabia) Research Board.

\subsection{Statistical Analysis}

Statistical Package for Social Sciences (version 16) was used for analysis and to perform Pearson Chi-square test for statistical significance (P value). The 95\% confidence level and confidence intervals were used. $P$ value less than 0.05 was considered statistically significant.

\section{Results}

In this study 715 Saudi volunteers were recruited, their ages ranging from 18 to 66 years with a mean age of 29.8 years. Out of the 715 contributors, 441/715 (61.7\%) were males and 274/715 (38.3\%) were females, giving males' females' ration of 1.60 to 1.00 . About $56.2 \%$ of the participants were younger than the age of 30 years, and the age distribution among males and females was relatively similar, as shown in Figure 1.

With regard to education level, the majority of the participants were with higher education level representing 411/715 (57.5\%) and the remaining 304/7715 $(42.5 \%)$ were with general education level. For both males and females the majority of participants were with higher education level representing 267/441 (60.5\%) and 144/274 (52.6\%) for males and females respectively, as showed in Table 1, in Figure 2.

With regard to the occupation, most of participants were at educational sector followed by military sector, representing 260/715 (36.4\%), and 105/715 (14.7\%), respectively. For males, most of the study subjects were at educational sector followed by military, constituting 156/441 (35.4\%) and 82/41 (18.6\%), in this order. For females most of the participants were at education sector followed by free work representing 104/274 (38\%) and 36/274 (13\%), in this order, as indicated in Table 1, Figure 1.

In respect to blood group, the majority of the study population were found with grop $\mathrm{B}+$ representing 174 participants, followed by $\mathrm{A}+, \mathrm{O}+, \mathrm{AB}+\mathrm{B}-\mathrm{ve}$, $A$-ve, AB-ve and O-ve, representing 165, 153, 47, 29, 20, 9, and 7 participants, in this order. However, there were 111 participants who didn't know their blood group, as shown in Figure 3.

Table 2 summarized the distribution of the study subjects by blood group and donation status. The majority of the previously donated people were those with blood group (O+), followed by $\mathrm{A}+$ and $\mathrm{B}+$ constituting 93, 92 and 73 persons, respectively. However, on calculation of the percentage of the donors within each blood group, figures vary, as shown in Figure 4. The majority of those gave a required donation were with blood group $\mathrm{A}+$, followed by $\mathrm{B}+$ and $\mathrm{O}+\& \mathrm{AB}+$ 


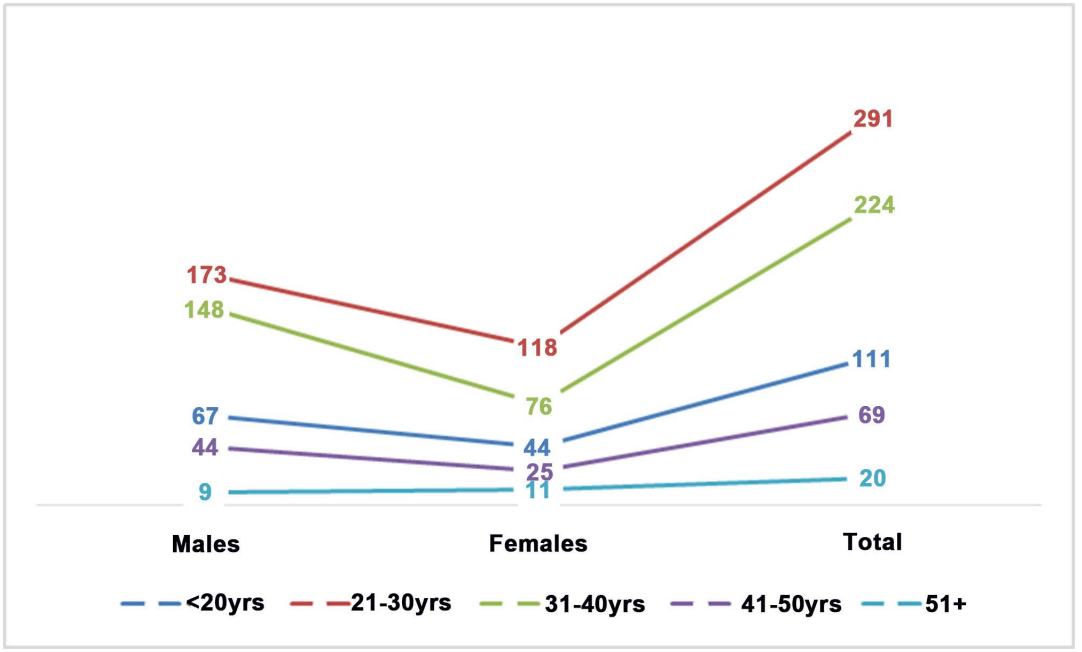

Figure 1. Description of the study population by age and sex.

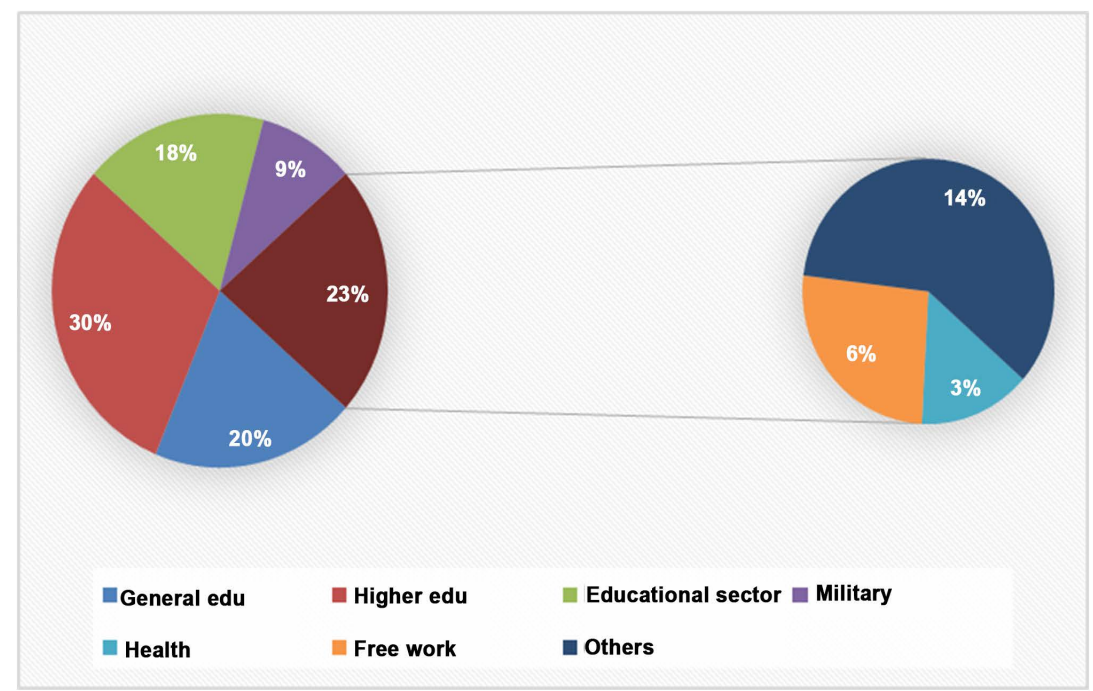

Figure 2. Description of study subjects by sex and demographical characteristics.

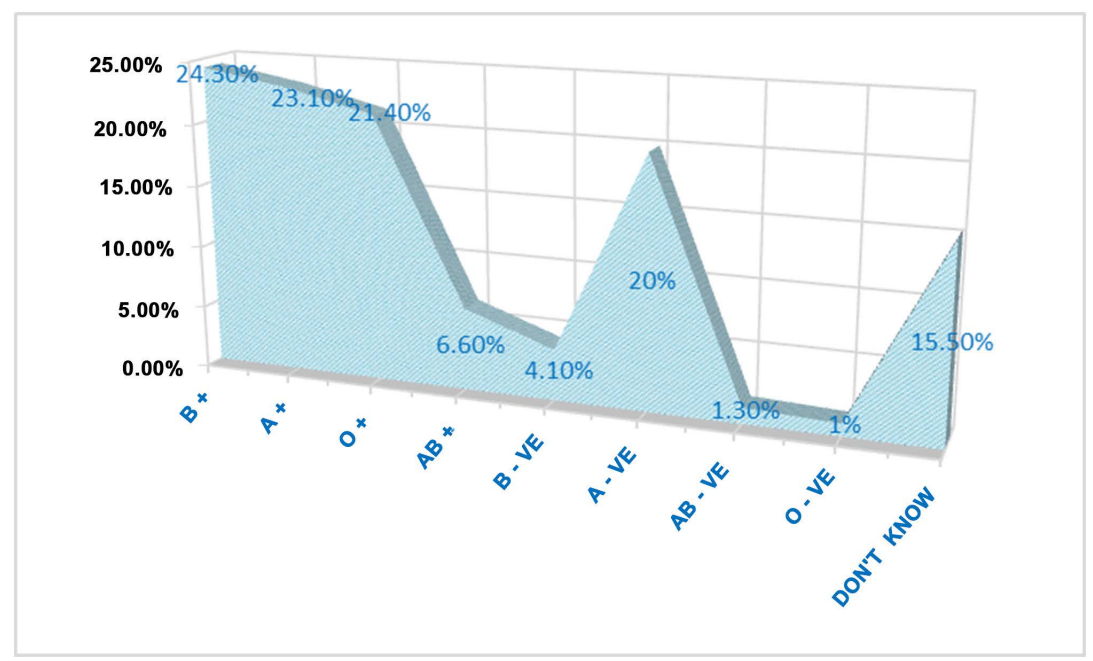

Figure 3. Description of the participants by blood group type. 


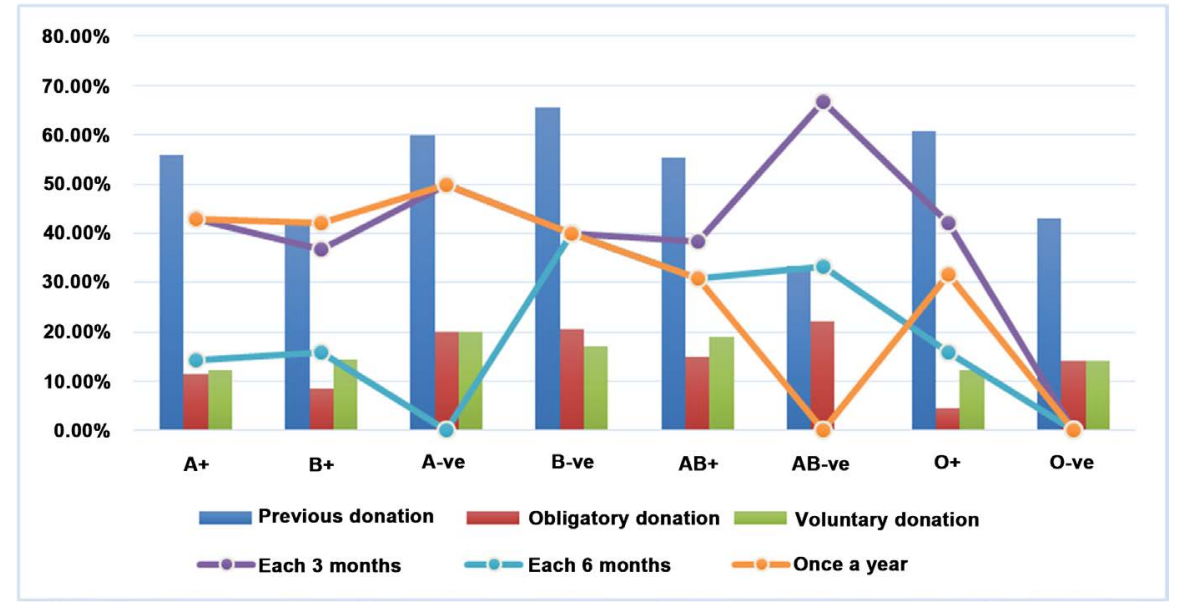

Figure 4. Proportions of study population by donation status in each blood group.

Table 1. Distribution of the participants by sex and level of education and occupational sector.

\begin{tabular}{ccccc}
\hline Variable & Category & Males & Females & Total \\
\hline Education & & & & \\
\hline \multirow{2}{*}{ Occupation } & Higher & 174 & 130 & 304 \\
& Total & 467 & 144 & 411 \\
& & & 274 & 715 \\
\hline \multirow{2}{*}{ Education sector } & 156 & 104 & 260 \\
& Military & 82 & 23 & 105 \\
& Health & 29 & 24 & 83 \\
& Free work & 53 & 36 & 208 \\
& Others & 121 & 87 & 715 \\
\hline
\end{tabular}

constituting 19, 15 and 7 persons, respectively. However, on calculation of the percentage of the donors within each blood group, figures vary, as shown in Figure 4. The majority of those gave a voluntary donation were with blood group $\mathrm{A}+$, followed by $\mathrm{B}+$ and $\mathrm{O}+$ constituting 35, 25 and 19 persons, respectively. However, on calculation of the percentage of the donors within each blood group, figures vary, as shown in Figure 4.

With regard to the frequency of blood donation, for those who donates each 3 months, most of them were with blood group $\mathrm{A}+$, followed by $\mathrm{O}+$ and $\mathrm{B}+$ representing 15, 8 and 7 persons, correspondingly. For those who donates once a year, most of them were with blood group $\mathrm{A}+$, followed by $\mathrm{B}+$ and $\mathrm{O}+$ representing 15, 8 and 6 persons, correspondingly. However, on calculation of the percentage of the donors within each blood group, figures vary, as indicated Table 2, in Figure 4. 
Table 2. Distribution of the study subjects by blood group and donation status.

\begin{tabular}{|c|c|c|c|c|c|c|c|c|c|c|}
\hline Variable & Category & $A+$ & $\mathrm{B}+$ & A-ve & B-ve & $\mathrm{AB}+$ & $A B$-ve & $\mathrm{O}+$ & O-ve & Total \\
\hline \multicolumn{11}{|c|}{ Previous donation } \\
\hline & Yes & 92 & 73 & 12 & 19 & 26 & 3 & 93 & 3 & 321 \\
\hline & Never & 73 & 101 & 8 & 10 & 21 & 6 & 60 & 4 & 283 \\
\hline & Total & 165 & 174 & 20 & 29 & 47 & 9 & 153 & 7 & 604 \\
\hline \multicolumn{11}{|c|}{ I gave an obligatory donation } \\
\hline & Yes & 19 & 15 & 4 & 6 & 7 & 2 & 7 & 1 & 61 \\
\hline & No & 81 & 104 & 8 & 10 & 19 & 6 & 69 & 4 & 301 \\
\hline \multicolumn{11}{|c|}{ I gave voluntary donation } \\
\hline & Yes & 35 & 25 & 4 & 5 & 9 & 0 & 19 & 1 & 98 \\
\hline & No & 136 & 149 & 16 & 24 & 38 & 9 & 134 & 6 & 512 \\
\hline & & 171 & 174 & 20 & 29 & 47 & 9 & 153 & 7 & 610 \\
\hline \multicolumn{11}{|c|}{ Donation frequency } \\
\hline & Each 3 months & 15 & 7 & 2 & 1 & 5 & 2 & 8 & 0 & 40 \\
\hline & Each 6 months & 5 & 3 & 0 & 2 & 4 & 1 & 3 & 0 & 18 \\
\hline & Once a year & 15 & 8 & 2 & 2 & 4 & 0 & 6 & 0 & 38 \\
\hline & infrequent & 0 & 1 & 0 & 0 & 0 & 0 & 2 & 0 & 3 \\
\hline & Total & 35 & 19 & 4 & 5 & 13 & 3 & 19 & 0 & 99 \\
\hline
\end{tabular}

The distribution of the study subjects by blood group and personal factors related donation status was summarized in Table 3. Notice: not all of the participants had responded to these questions. On asking them "Will you intend to donate in the future", The great majority of the respondents were with group A+ followed by group $\mathrm{O}+$ and $\mathrm{B}+$ representing 78,73 , and 67 , correspondingly. On asking them "If there is announcement for your blood group will response?", The great majority of the respondents were with group $\mathrm{A}+$ followed by group $\mathrm{O}+\& \mathrm{~B}+$ representing 122, 107 for both, correspondingly. On asking them "are worry from blood donation?", about 189 participants were found to fear from pain and most of them were with group $\mathrm{B}+$ followed by group $\mathrm{A}+$ and $\mathrm{O}+$ representing 71, 45, 32 participants, in that order. About 111 participants were found to fear from infection and most of them were with group A+ followed by group $\mathrm{B}+$ and $\mathrm{O}+$ representing $36,29,27$ participants, in that order.

\section{Discussion}

In present study, data regarding blood groups and donation related factors were obtained from a random Saudi population sample. Saudi Arabia represent a broad spectrum image for Araba ethnic groups and gulf Arabia population. To the best of our knowledge there is no such report from Saudi Arabia, thus, we intended to highlight this area in order to stimulate a comprehensive study in this context. 
Table 3. Distribution of the study subjects by blood group and personal factors related donation status.

\begin{tabular}{ccccccccccc}
\hline Variable & Category & A+ & B + & A-ve & B-ve & AB + & AB-ve & O+ & O-ve & Total \\
\hline Will you intend to donate in the future & & & & & & \\
\hline Yes & 78 & 67 & 12 & 18 & 26 & 2 & 73 & 3 & 279 \\
No & 87 & 107 & 8 & 11 & 21 & 7 & 80 & 4 & 325 \\
Total & 165 & 174 & 20 & 29 & 47 & 9 & 153 & 7 & 604 \\
\hline If there is annoucement for your blood group will response? & & & & \\
\hline Yes & 122 & 107 & 12 & 15 & 30 & 3 & 107 & 3 & 399 \\
May be & 25 & 35 & 3 & 9 & 4 & 3 & 26 & 2 & 107 \\
No & 18 & 32 & 5 & 5 & 13 & 3 & 19 & 2 & 97 \\
\hline Are worry from blood donation & & & & & & \\
\hline Yes (pain) & 45 & 71 & 8 & 5 & 23 & 2 & 32 & 3 & 189 \\
Yes (infection) & 36 & 29 & 4 & 3 & 8 & 4 & 27 & 0 & 111 \\
No & 84 & 74 & 8 & 21 & 16 & 3 & 94 & 4 & 304 \\
Total & 165 & 174 & 20 & 29 & 47 & 9 & 153 & 7 & 604 \\
\hline
\end{tabular}

In the current study, blood group $\mathrm{B}+(24.3 \%)$ represented the major exist group among studied population followed by $\mathrm{A}+(23.1 \%)$ and $\mathrm{O}+(21.4 \%)$. Globally, group $\mathrm{O}$ had the highest frequency $(49.10 \%)$ followed by A $(28.28 \%), \mathrm{B}$ (18.56\%) and $\mathrm{AB}(4.05 \%)$ [12]. However, most of studies dealt with group $\mathrm{O}$ and $\mathrm{RhD}$. Earlier studies have revealed that the percentage of blood group $\mathrm{O}$ to be 49.10\% in Mauritania [12], 46.6\% in the United States [13], 42.3\% in Denmark [14], 38.9\% in Sweden [14], and 34\% in China [15]. The proportion of those with $\mathrm{RhD}$-negative ( $\mathrm{RhD}-$ ) blood has been reported to be $14.6 \%$ in the USA [13], 17.9\% in Sweden and Denmark [14] and between $0.4 \%$ and $1.0 \%$ in China [15]; this also varies among different races or ethnic populations [13] [14] [16]. In the USA, the percentage of group O varies from $39.8 \%$ in Asian donors to $56.5 \%$ in Hispanic donors, and the proportion of $\mathrm{RhD}-$ varies from $1.7 \%$ in Asian donors to $17.3 \%$ in White non-Hispanic donors [13]. However, a comprehensive population based study is required in Saudi Arabia to design more specific reference intervals for $\mathrm{ABO}$ and $\mathrm{RhD}$ system. Moreover, Voluntary blood donation could be better met with specific blood donor information, education, motivation, and recruitment strategies focusing on the myths and misconceptions prevalent in the donor demographic area of that particular region, specifically targeting high-school children in countries developing a volunteer donor base [17].

Due to every time call for rare blood group donation, we tried to link the response for blood donation with specific blood group regardless of outnumber of the group of rarity. With regard to the previous donation, individuals within group $\mathrm{B}$-ve presented the great proportion followed by $\mathrm{O}-\mathrm{RhD}+$ and $\mathrm{A}$-ve. On 
the other hand, the most response to voluntary donation was those within group A-ve followed by $\mathrm{AB}+$.

People within $\mathrm{AB}$-ve represent the highest percentage in donation each 3 months followed by A-ve. Donation once a year was dominated within A-ve group. These findings showed that individuals with Rhesus negative are more likely to donate.

Within the future intending to donated, group A+ were more likely to be involved followed by $\mathrm{O}+$ and $\mathrm{B}+$. Those with relatively rare blood groups were relatively less likely to be involved in future blood donation. With regard to the response announcement for, which usually will be for rare blood groups, group $\mathrm{B}+$ followed by $\mathrm{A}+$ and $\mathrm{O}+$ are the greatest respondent, their blood groups are available in all populations [18].

With regard to the worry from blood donation due to pain and infection, many persons within group $\mathrm{B}+$ fear form pain associated with blood collection. It was previously reported that recurring barriers for people were hemoglobin deferral, fear of needles and pain, social exclusion, lack of awareness, negative attitudes and accessibility problems [19]. Complications associated with blood donation significantly lower odds of subsequent donations. Complications varied significantly between various blood banks. Pre-donation hydration was effective in limiting complications with generalized symptoms [20]. This study may present platform for further studies in context in addition to the relationship between blood group and behavioral act.

The limitations of the present study are: its cross-sectional being; the including of the blood group depending on individual reporting.

\section{Conclusion}

The major group among Saudi population is group B+ followed by group A+ and $\mathrm{O}+$. Individuals with rare blood groups were less likely to participate in blood donation programs, which necessitate the need for educational programs using motivating factors. A comprehensive study including a big sample size is required in order to find out reference intervals for different groups with various ethnic groups in Saudi Arabia. Further research is needed to gain more insight in the role of these groups in the attitude of blood donation.

\section{Acknowledgements}

Authors would like to thank all participants in this study for their appreciated participation.

\section{Conflicts of Interest}

The authors declare no conflicts of interest regarding the publication of this paper.

\section{References}

[1] Shi, L., Wang, J., Liu, Z., et al. (2014) Blood Donor Management in China. Transfu- 
sion Medicine and Hemotherapy, 41, 273-282. https://doi.org/10.1159/000365425

[2] Uma, S., Arun, R. and Arumugam, P. (2013) The Knowledge, Attitude and Practice towards Blood Donation among Voluntary Blood Donors in Chennai, India. Journal of Clinical and Diagnostic Research, 7, 1043-1046.

[3] WHO Guidelines Approved by the Guidelines Review Committee. (2010) Towards 100\% Voluntary Blood Donation: A Global Framework for Action. Geneva: World Health Organization.

[4] Anstee, D.J. (2010) The Relationship between Blood Groups and Disease. Blood, 115, 4635-4643. https://doi.org/10.1182/blood-2010-01-261859

[5] Liu, J., Zhang, S., Wang, Q., Shen, H., Zhang, Y. and Liu, M. (2017) Frequencies and Ethnic Distribution of ABO and RhD Blood Groups in China: A Population-Based Cross-Sectional Study. BMJ Open, 7, e018476.

https://doi.org/10.1136/bmjopen-2017-018476

[6] Volken, T., Crawford, R.J., Amar, S., Mosimann, E., Tschaggelar, A. and Taleghani, B.M. (2017) Blood Group Distribution in Switzerland-A Historical Comparison. Transfusion Medicine and Hemotherapy, 44, 210-216. https://doi.org/10.1159/000479191

[7] Delaney, M., Harris, S., Haile, A., Johnsen, J., Teramura, G. and Nelson, K. (2015) Red Blood Cell Antigen Genotype Analysis for 9087 Asian, Asian American, and Native American Blood Donors. Transfusion, 55, 2369-2375.

https://doi.org/10.1111/trf.13163

[8] Karafin, M.S., Field, J.J., Gottschall, J.L. and Denomme, G.A. (2015) Barriers to Using Molecularly Typed Minority Red Blood Cell Donors in Support of Chronically Transfused Adult Patients with Sickle Cell Disease. Transfusion, 55, 1399-1406. https://doi.org/10.1111/trf.13037

[9] Noizat-Pirenne, F. (2003) Immunohematologic Characteristics in the Afro-Caribbean Population. Consequences for Transfusion Safety. Transfusion Clinique et Biologique, 10, 185-191. https://doi.org/10.1016/S1246-7820(03)00042-9

[10] Noizat-Pirenne, F., Lee, K., Pennec, P.Y., et al. (2002) Rare RHCE Phenotypes in Black Individuals of Afro-Caribbean Origin: Identification and Transfusion Safety. Blood, 100, 4223-4231. https://doi.org/10.1182/blood-2002-01-0229

[11] Al-Mawali, A., Pinto, A.D., Al-Busaidi, R., Al-Lawati, R.H. and Morsi, M. (2018) Comprehensive Haematological Indices Reference Intervals for a Healthy Omani Population: First Comprehensive Study in Gulf Cooperation Council (GCC) and Middle Eastern Countries Based on Age, Gender and ABO Blood Group Comparison. PLoS ONE, 13, e0194497.

[12] Hamed, C.T., Bollahi, M.A., Abdelhamid, I., et al. (2012) Frequencies and Ethnic Distribution of $\mathrm{ABO}$ and $\mathrm{Rh}(\mathrm{D})$ Blood Groups in Mauritania: Results of First Nationwide Study. International Journal of Immunogenetics, 39, 151-154. https://doi.org/10.1111/j.1744-313X.2011.01064.x

[13] Garratty, G., Glynn, S.A. and McEntire, R. (2004) Retrovirus Epidemiology Donor Study. ABO and Rh(D) Phenotype Frequencies of Different Racial/Ethnic Groups in the United States. Transfusion, 44, 703-706. https://doi.org/10.1111/j.1537-2995.2004.03338.x

[14] Vasan, S.K., Rostgaard, K., Majeed, A., et al. (2016) ABO Blood Group and Risk of Thromboembolic and Arterial Disease: A Study of 1.5 Million Blood Donors. Circulation, 133, 1457. https://doi.org/10.1161/CIRCULATIONAHA.115.017563

[15] Guo, N., Wang, J., Ness, P., et al. (2012) Demographics of Apheresis Platelet Donors 
in Five Blood Centers in China. Transfusion, 52, 560-566. https://doi.org/10.1111/j.1537-2995.2011.03328.x

[16] Loua, A., Lamah, M.R., Haba, N.Y., et al. (2007) Frequency of Blood Groups ABO and Rhesus D in the Guinean Population. Transfusion Clinique et Biologique, 14, 435-439. https://doi.org/10.1016/j.tracli.2007.12.008

[17] Mishra, S.K., Sachdev, S., Marwaha, N. and Avasthi, A. (2016) Study of Knowledge and Attitude among College-Going Students toward Voluntary Blood Donation from North India. Journal of Blood Medicine, 7, 19-26.

[18] Liumbruno, G.M. and Franchini, M. (2014) Hemostasis, Cancer, and ABO Blood Group: The Most Recent Evidence of Association. Journal of Thrombosis and Thrombolysis, 38, 160-166. https://doi.org/10.1007/s11239-013-1027-4

[19] Klinkenberg, E.F., Huis In't Veld, E.M.J., et al. (2018) Blood Donation Barriers and Facilitators of Sub-Saharan African Migrants and Minorities in Western High-Income Countries: A Systematic Review of the Literature. Transfusion Medicine. https://doi.org/10.1111/tme.12517

[20] Agarwal, R.K., Periyavan, S., Dhanya, R., et al. (2016) Complications Related to Blood Donation: A Multicenter Study of the Prevalence and Influencing Factors in Voluntary Blood Donation Camps in Karnataka, India. Asian Journal of Transfusion Science, 10, 53-58. https://doi.org/10.4103/0973-6247.165840 